\title{
Overview of healthcare in the UK
}

\author{
Konstantina Grosios • Peter B. Gahan • Jane Burbidge
}

Received: 1 September 2010 / Accepted: 27 September 2010 / Published online: 25 October 2010

(C) European Association for Predictive, Preventive and Personalised Medicine 2010

\begin{abstract}
The National Health System in the UK has evolved to become one of the largest healthcare systems in the world. At the time of writing of this review (August 2010) the UK government in its 2010 White Paper "Equity and excellence: Liberating the NHS" has announced a strategy on how it will "create a more responsive, patient-centred NHS which achieves outcomes that are among the best in the world". This review article presents an overview of the UK healthcare system as it currently stands, with emphasis on Predictive, Preventive and Personalised Medicine elements. It aims to serve as the basis for future EPMA articles to expand on and present the changes that will be implemented within the NHS in the forthcoming months.
\end{abstract}

Keywords UK $\cdot$ Healthcare system $\cdot$ National health system $\cdot$ NHS

\section{Introduction}

The UK healthcare system, National Health Service (NHS), came into existence in the aftermath of the

\section{K. Grosios is National Representative of EPMA in UK.}

\section{K. Grosios $(\bowtie)$}

Biomedical and Health Research Centre \& Leeds Cancer

Research UK Centre, University of Leeds,

Leeds LS2 9JT, UK

e-mail: k.grosios@leeds.ac.uk

P. B. Gahan

Anatomy \& Human Sciences, King's College London,

London SE1 1UL, UK

J. Burbidge

NHS Yorkshire and the Humber Strategic Health Authority,

Blenheim House,

Leeds LS1 4PL, UK
Second World War and became operational on the 5th July 1948. It was first proposed to the Parliament in the 1942 Beveridge Report on Social Insurance and Allied Services and it is the legacy of Aneurin Bevan, a former miner who became a politician and the then Minister of Health. He founded the NHS under the principles of universality, free at the point of delivery, equity, and paid for by central funding [1]. Despite numerous political and organisational changes the NHS remains to date a service available universally that cares for people on the basis of need and not ability to pay, and which is funded by taxes and national insurance contributions.

Health care and health policy for England is the responsibility of the central government, whereas in Scotland, Wales and Northern Ireland it is the responsibility of the respective devolved governments. In each of the UK countries the NHS has its own distinct structure and organisation, but overall, and not dissimilarly to other health systems, healthcare comprises of two broad sections; one dealing with strategy, policy and management, and the other with actual medical/clinical care which is in turn divided into primary (community care, GPs, Dentists, Pharmacists etc.), secondary (hospitalbased care accessed through GP referral) and tertiary care (specialist hospitals). Increasingly distinctions between the two broad sections are becoming less clear. Particularly over the last decade and guided by the "Shifting the Balance of Power: The Next Steps" (2002) and "Wanless" (2004) reports, gradual changes in the NHS have led to a greater shift towards local rather than central decision making, removal of barriers between primary and secondary care and stronger emphasis on patient choice $[2,3]$. In 2008 the previous government reinforced this direction in its health strategy "NHS Next Stage Review: High Quality Care for All" (the Darzi Review), and in 
2010 the current government's health strategy, "Equity and excellence: Liberating the NHS", remains supportive of the same ideas, albeit through possibly different mechanisms $[4,5]$.

The UK government has just announced plans that according to some will produce the most radical change in the NHS since its inception. In the 12th July 2010 White Paper "Equity and excellence: Liberating the NHS", the current Conservative-Liberal Democrat coalition government outlined a strategy on how it will "create a more responsive, patient-centred NHS which achieves outcomes that are among the best in the world" [5].

This review article will therefore present an overview of the UK healthcare system as it currently stands with the aim to serve as the basis for future EPMA articles to expand and present the changes that will be implemented within the NHS in the forthcoming months.

\section{The NHS in 2010}

The Health Act 2009 established the "NHS Constitution" which formally brings together the purpose and principles of the NHS in England, its values, as they have been developed by patients, public and staff and the rights, pledges and responsibilities of patients, public and staff [6]. Scotland, Northern Ireland and Wales have also agreed to a high level statement declaring the principles of the NHS across the UK, even though services may be provided differently in the four countries, reflecting their different health needs and situations.

The NHS is the largest employer in the UK with over 1.3 million staff and a budget of over $£ 90$ billion [7, 8]. In 2008 the NHS in England alone employed 132,662 doctors, a 4\% increase on the previous year, and 408,160 nursing staff (Table 1). Interestingly the Kings Fund estimates that, while the total number of NHS staff increased by around 35\% between 1999 and 2009, over the same period the number of managers increased by $82 \%$. As a proportion of NHS staff, the number of managers rose from 2.7 per cent in 1999 to 3.6 per cent in 2009 (www.kingsfund.org.uk). In $2007 / 8$, the UK health spending was $8.5 \%$ of Gross Domestic Product (GDP) - with 7.3\% accounting for public and $1.2 \%$ for private spending. The net NHS expenditure per head across the UK was lowest in England $(£ 1,676)$ and highest in Scotland $(£ 1,919)$ with Wales and Northern Ireland at approximately the same level $(£ 1,758$ and $£ 1,770$, respectively) [8].

The overall organisational structure of the NHS in England, Scotland, Wales and Northern Ireland in 2010 is shown in Fig. 1. In England the Department of Health is responsible for the direction of the NHS, social care and public health and delivery of healthcare by developing policies and strategies, securing resources, monitoring performance and setting national standards [9]. Currently, 10 Strategic Health Authorities manage the NHS at a local level, and Primary Care Trusts (PCTs), which currently control $80 \%$ of the NHS' budget, provide governance and commission services, as well as ensure the availability of services for public heath care, and provision of community services. Both, SHAs and PCTs will cease to exist once the plans outlined in the 2010 White Paper become implemented (see section below). NHS Trusts operate on a "payment by results" basis and obtain most of their income by providing healthcare that has been commissioned by the practice-based commissioners (GPs, etc.) and PCTs. The main types of Trusts include Acute, Care, Mental Health, Ambulance, Children's and Foundation Trusts. The latter were created as non-profit making entities, free of government control but also increased financial obligations and are regulated by an independent Monitor. The Care Quality Commission regulates independently health and adult social care in England overall. Other specialist bodies provide financial (e.g. Audit Commission, National Audit Office), treatment/services (e.g. National Patient Safety Agency, Medicines and Healthcare Products Regulatory Agency) and professional (e.g. British Medical Association) regulation. The National Institute for Health and Clinical
Table 1 The distribution of NHS workforce according to main staff groups in the UK in 2008 (NHS Information Centre: www.ic.nhs.uk)

\begin{tabular}{llc}
\hline NHS main staff groups & No. of staff & \% of total NHS workforce \\
\hline All doctors & 132,662 & 9.6 \\
Qualified ambulance staff & 17,451 & 1.2 \\
Scientific, therapeutic \& technical staff & 142,558 & 10.4 \\
Qualified nursing staff & 408,160 & 29.8 \\
Support to clinical staff & 355,010 & 25.9 \\
Support to GPs & 58,572 & 4.3 \\
NHS infrastructure & 219,064 & 16 \\
Other GP practice staff & 92,436 & 6.8 \\
Other & 353 & 0.02 \\
Total & $1,368,693$ & 100 \\
\hline
\end{tabular}


Excellence (NICE) was established in 1999 as the body responsible for developing national guidelines and standards related to, health promotion and prevention, assessment of new and existing technology (including medicines and procedures) and treatment and care clinical guidance, available across the NHS. The health research strategy of the NHS is being implemented through National Institute of Health Research (NIHR), the total budget for which was in 2009/10 close to $£ 1$ billion (www.nihr.ac.uk) [10].

Section 242 of the NHS Act states that Trusts have a legal duty to engage and involve patients and the public. Patient experience information/feedback is formally gathered nationally by annual survey (by the Picker Institute) and is part of the NHS Acute Trust performance framework. The Patient Advice Liaison Service (PALS) and Local Involvement Networks (LINks) support patient feedback and involvement. Overall, inpatients and outpatients surveys have revealed that patients rate the care they receive in the NHS high and around three-quarters indicate that care has been very good or excellent [11].

In Scotland, NHS Boards have replaced Trusts and provide an integrated system for strategic direction, performance management and clinical governance, whereas in Wales, the National Delivery Group, with advice from the National Advisory Board, is the body performing these functions (www.show.scot.nhs.uk; www.wales.nhs.uk). Scottish NHS and Special Boards deliver services, with care for specific conditions delivered through Managed Clinical Networks. Clinical guidelines are published by the Scottish Intercollegiate Guidelines Network (SIGN) and the Scottish Medicines Consortium (SMC) advices on the use of new drugs in the Scottish NHS. In Wales, Local Heath Boards (LHBs) plan, secure and deliver healthcare services in their areas and there are 3 NHS Trusts providing emergency, cancer care and public health services nationally. In Northern Ireland, a single body, the Health and Care Board is overseeing commissioning, performance and resource management and improvement of healthcare in the country and six Health and Social Care Trusts deliver these services (www.hscni.net). A number of health agencies support ancillary services and deal with a wide range of health and care issues including cancer screening, blood transfusion, public health etc. In Wales Community Health Councils are statutory lay bodies advocating the interests of the public in the health service in their district and in Northern Ireland the Patient and Client Council represent patients, clients and carers.

\section{Predictive, Preventive and Personalised Medicine (PPPM) in the NHS}

Like other national healthcare systems, predictive, preventive and/or personalised medicine services within the
NHS have traditionally been offered and are part of disease diagnosis and treatment. Preventive medicine, unlike predictive or personalised medicine, is its own established entity and relevant services are directed by Public Health and offered either via GP, community services or hospitals. Patient-tailored treatment has always been common practice for good clinicians in the UK and any other healthcare system. The terms predictive and personalised medicine though are evolving to describe a much more technologically advanced way of diagnosing disease and predicting response to the standard of care, in order to maximise the benefit for the patient, the public and the health system.

References to predictive and personalised medicine are increasingly being introduced in NHS related information. The NHS Choices website describes how patients can obtain personalised advice in relation to their condition, and offers information on predictive blood test for disease such as TB or diabetes. The NIHR through NHS-supported research and together with academic and commercial collaborating networks is investing a significant proportion of its budget in validating predictive and preventive therapeutic interventions [10]. The previous government considered the development of preventive, people-centred and more productive healthcare services as the means for the NHS to respond to the challenges that all modern healthcare systems are facing in the 21 st century, namely, high patient expectation, ageing populations, harnessing of information and technological advancement, changing workforce and evolving nature of disease [12]. Increased emphasis on quality (patient safety, patient experience and clinical effectiveness) has also supported innovation in early diagnosis and PPPM-enabling technologies such as telemedicine.

A number of preventive services are delivered through the NHS either via GP surgeries, community services or hospitals depending on their nature and include:

- The Cancer Screening programmes in England are nationally coordinated and include Breast, Cervical and Bowel Cancer Screening. There is also an informed choice Prostate Cancer Risk Management programme (www.cancerscreening.nhs.uk).

- The Child Health Promotion Programme is dealing with issues from pregnancy and the first 5 years of life and is delivered by community midwifery and health visiting teams [13].

- Various immunisation programmes from infancy to adulthood, offered to anyone in the UK for free and generally delivered in GP surgeries.

The Darzi review set out six key clinical goals in relation to improving preventive care in the UK including, 1) tackling obesity, 2) reducing alcohol harm, 3) treating drug addiction, 
4) reducing smoking rates, 5) improving sexual health and 6) improving mental health. Preventive programmes to address these issues have been in place over the last decades in different forms and through different initiatives, and include:

- Assessment of cardiovascular risk and identification of people at higher risk of heart disease is generally preformed through GP surgeries.

- Specific preventive programmes (e.g. suicide, accident) in local schools and community

- Family planning services and prevention of sexually transmitted disease programmes, often with a emphasis on young people

- A variety of prevention and health promotion programmes related to lifestyle choices are delivered though GPs and community services including, alcohol and smoking cessation programmes, promotion of healthy eating and physical activity. Some of these have a specific focus such as health promotion for older people (e.g. Falls Prevention).

\section{White paper 2010 - Equity and excellence: liberating the NHS}

The current government's 2010 "Equity and excellence: Liberating the NHS" White Paper has set out the vision of the future of an NHS as an organisation that still remains true to its founding principle of, available to all, free at the point of use and based on need and not ability to pay. It also continues to uphold the principles and values defined in the NHS Constitution. The future NHS is part of the Government's Big Society which is build on social solidarity and entails rights and responsibilities in accessing collective healthcare and ensuring effective use of resources thus delivering better health. It will deliver healthcare outcomes that are among the best in the world. This vision will be implemented through care and organisation reforms focusing on four areas: a) putting patients and public first, b) improving on quality and health outcomes, c) autonomy, accountability and democratic legitimacy, and d) cut bureaucracy and improve efficiency [5]. This strategy makes references to issues that are relevant to PPPM which indicates the increasing influence of PPPM principles within the NHS.

According to the White Paper the principle of "shared decision-making" (no decision about me without me) will be at the centre of the "putting emphasis on patient and public first" plans. In reality this includes plans emphasising the collection and ability to access by clinicians and patients all patient- and treatment-related information. It also includes greater attention to Patient-Reported Outcome Measures, greater choice of treatment and treatment-provider, and
Fig. 1 Organisation of the NHS in England, Scotland, Wales and Northern Ireland, in 2010

importantly personalised care planning (a "not one size fits all" approach). A newly created Public Health Service will bring together existing services and place increased emphasis on research analysis and evaluation. Health Watch England, a body within the Care Quality Commission, will provide a stronger patient and public voice, through a network of local Health Watches (based on the existing Local Involvement Networks - LINks).

The NHS Outcomes Framework sets out the priorities for the NHS. Improving on quality and health outcomes, according to the White Paper, will be achieved through revising goals and healthcare priorities and developing targets that are based on clinically credible and evidencebased measures. NICE have a central role in developing recommendations and standards and will be expected to produce 150 new standards over the next 5 years. The government plans to develop a value-based pricing system for paying pharmaceutical companies for providing drugs to the NHS. A Cancer Drug Fund will be created in the interim to cover patient treatment.

The abolition of SHAs and PCTs, are being proposed as means of providing greater autonomy and accountability. GP Consortia supported by the NHS Commissioning Board will be responsible for commissioning healthcare services. The introduction of this type of "health management organisations" has been somewhat controversial but possibly not totally unexpected $[14,15]$. The transfer of PCT health improvement function to local authorities aims to provide increased democratic legitimacy.

\section{Challenges facing the UK healthcare system}

Overall the health, as well as ideological and organisational challenges that the UK Healthcare system is facing are not dissimilar to those faced by many national healthcare systems across the world. Life expectancy has been steadily increasing across the world with ensuing increases in chronic diseases such as cancer and neurological disorders. Negative environment and lifestyle influences have created a pandemic in obesity and associated conditions such as diabetes and cardiovascular disease. In the UK, coronary heart disease, cancer, renal disease, mental health services for adults and diabetes cover around $16 \%$ of total National Health Service (NHS) expenditure, $12 \%$ of morbidity and between $40 \%$ and $70 \%$ of mortality [3]. Across Western societies, health inequalities are disturbingly increasing, with minority and ethnic groups experiencing most serious illnesses, premature death and disability. The House of Commons Health Committee warns that whilst 

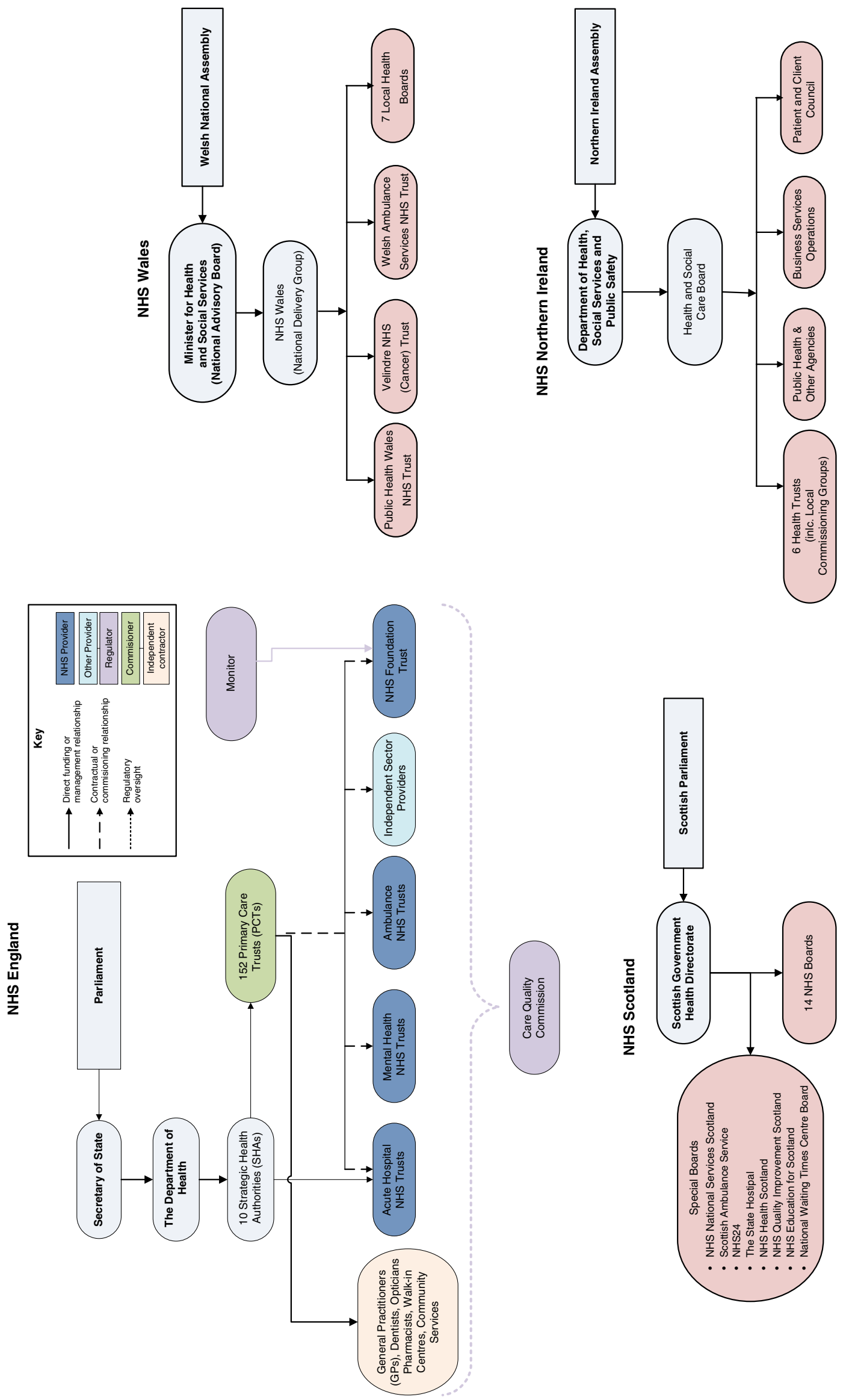
the health of all groups in England is improving, over the last 10 years health inequalities between the social classes have widened - the gap has increased by $4 \%$ for men, and by $11 \%$ for women-due to the fact that the health of the rich is improving much quicker than that of the poor [16]. The focus and practice of healthcare services is being transformed from traditionally offering treatment and supportive or palliative care to increasingly dealing with the management of chronic disease and rehabilitation regimes, and offering disease prevention and health promotion interventions. Pay-for-performance, changes in regulation together with cost-effectiveness and pay for medicines issues are becoming a critical factor in new interventions reaching clinical practice $[17,18]$.

Preventive medicine is solidly established within the UK Healthcare System, and predictive and personalised approaches are increasingly becoming so. Implementation of PPPM interventions may be the solution but also the cause of the health and healthcare challenges and dilemmas that health systems such as the NHS are facing [19]. The efficient introduction of PPPM requires scientific understanding of disease and health, and technological advancement, together with comprehensive strategies, evidence-based health policies and appropriate regulation. Critically, education of healthcare professionals, patients and the public is also paramount. There is little doubt however that harnessing PPPM appropriately can help the NHS achieve its vision of delivering healthcare outcomes that will be among the best in the world.

\section{References}

1. Delamothe T. NHS at 60: founding principles. BMJ. 2008;336:1216-8.

2. Shifting the Balance of Power: The Next Steps. Department of Health publications. 2002. www.dh.gov.uk/en/Publicationsand statistics/Publications/PublicationsPolicyAndGuidance/DH 4008424

3. Wanless D. Securing good health for the whole population: Final report-February 2004. www.dh.gov.uk/en/Publicationsandstatistics/ Publications/PublicationsPolicyAndGuidance/DH_4074426
4. Professor the Lord Darzi of Denham KBE High quality care for all: NHS Next Stage Review final report. Department of Health publications. 2008. www.dh.gov.uk/en/Publicationsandstatistics/ Publications/PublicationsPolicyAndGuidance/DH_085825

5. White paper Equity and excellence: Liberating the NHS. Department of Health publications. 2010. www.dh.gov.uk/en/ Publicationsandstatistics/Publications/PublicationsPolicyAnd Guidance/DH 117353

6. The NHS Constitution for England. Department of Health publications. 2009. www.dh.gov.uk/en/Publicationsandstatistics/ Publications/PublicationsPolicyAndGuidance/DH 093419

7. NHS Hospital and Community Health Services: Medical and Dental staff England 1998-2008. The NHS Information Centre. 2009. www.ic.nhs.uk/webfiles/publications/nhsstaff2008/medandden/ Medical\%20and\%20Dental\%20bulletin\%201998-2008.pdf

8. House of Commons Health Committee: Public Expenditure on Health and Personal Social Services. The House of Commons. 2008. www.publications.parliament.uk/pa/cm200809/cmselect/ cmhealth/cmhealth.htm

9. The DH Guide A guide to what we do and how we do it. Department of Health publications. 2007. http://www.dh.gov.uk/ en/Publicationsandstatistics/Publications/index.htm

10. NIHR Annual Report 2009/10: Embedding Health Research. National Institute for Health Research. 2010. www.nihr.ac.uk/ Pages/default.aspx

11. Leatherman S. and Sutherland K. Patient and Public Experience in the NHS. The Health Foundation. 2007. www.health.org.uk/ publications/research_reports/patient_and_public.html

12. NHS 2010-2015: from good to great. Preventative, peoplecentred, productive. Department of Health publications. 2009. www.dh.gov.uk/en/Publicationsandstatistics/Publications/Publi cationsPolicyAndGuidance/DH_109876

13. Updated Child Health Promotion Programme. Department of Health publications. 2009. webarchive.nationalarchives.gov.uk/+/www.dh. gov.uk/en/Publicationsandstatistics/Publications/DH_083645

14. Klein R. What does the future hold for the NHS at 60 ? BMJ. 2008;337:a549.

15. Ham C (2007) Clinically integrated systems: the next step in English health reform? Briefing paper. London Nuffield Trust

16. Health Inequalities Third Report of Session 2008-09. House of Commons Health Committee. 2009; Volume I. www.publications. parliament.uk/pa/cm200809/cmselect/cmhealth/286/28602.htm

17. Clinicians, services and commissioning in chronic disease management in the NHS The need for coordinated management programmes. Report of a joint working party of the Royal College of Physicians of London, the Royal College of General Practitioners and the NHS Alliance. 2004. www.rcgp.org.uk/PDF/ Corp_chronic_disease_nhs.pdf

18. Hughes DA. From NCE to NICE: the role of pharmacoeconomics. Br J Clin Pharmacol. 2010;70:317-9.

19. Griggs JJ. Personalized medicine: a perk of privilege? Clin Pharmacol Ther. 2009;86:21-3. 